\title{
Entry and technology transfer in a Cournot model
}

\author{
Yutian Chen ${ }^{1}$, Debapriya Sen ${ }^{2}$ \\ (1. Department of Economics, California State University, Long Beach 90840, USA; \\ 2. Department of Economics, Ryerson University, Toronto M5B 2K3, Canada)
}

\begin{abstract}
This work studies entry and technology transfer in a Cournot model where there are two domestic firms. A foreign firm has a patent on a technological innovation that reduces the costs of all firms. The foreign firm can license the innovation to one or both domestic firms. The authors consider two standard licensing policies: (1) auction policy and (2) unit royalty policy. The foreign firm can license the innovation either by staying outside the domestic market, or it can enter the market, license the innovation and compete with the domestic firms. The authors show that (1) when the foreign firm stays outside, it is never optimal for it to use royalties, (2) if it licenses the innovation by entering the industry, then royalties could be optimal and (3) when it decides on its entry strategy by taking its optimal licensing policies into account, it always finds it optimal to enter the domestic market.
\end{abstract}

Key words: licensing; Cournot competition; entry

\section{Introduction}

International technology transfer across firms has grown substantially in recent years. When an efficient foreign firm transfers its technology to relatively less efficient domestic firms, it raises several interesting questions. In this work, the authors focus on two key interrelated questions. First, what is the optimal mode of technology transfer? Second, is it optimal for the foreign firm to just sell its technology without entering the domestic market, or should it enter the market as well?

In this era of globalization when entry barriers are not generally stringent, the second question assumes particular significance. The authors address these questions in a simple theoretical model, where there are two domestic firms that compete as Cournot duopolists in the domestic market. A foreign firm has a patent on a new technological innovation that reduces the costs of all firms. The foreign firm can license its technology to one or both domestic firms by using either of the two standard licensing policies: (1) auction (which is in effect an upfront fee policy where the fee is collected via an auction) and (2) unit royalty. The foreign firm also has two entry strategies in that it can license its technology either by staying outside the domestic market or it can enter the market, license its technology and then compete with the domestic firms. The authors obtain the following results.

First, when the foreign firm transfers its technological innovation by staying outside the domestic market, it is never optimal to use a royalty policy. For relatively insignificant innovations, it is optimal to license the innovation to both domestic firms using an auction. For relatively significant innovations, it is optimal to auction off only one license. Second, when the foreign firm transfers its innovation by entering the industry, a royalty

\footnotetext{
Yutian Chen, Ph.D., Department of Economics, California State University; research fields: industrial organization, game theory.

Debapriya Sen, Ph.D., Department of Economics, Ryerson University; research fields: industrial organization, microeconomic theory.
} 
policy could be optimal. Specifically, the optimal policy is to sell the innovation to both firms using royalty for relatively insignificant innovations. For relatively significant innovations, again it is optimal to auction off only one license. Third, when the foreign firm decides on its entry strategy by taking its optimal licensing policies into account, it always finds that it is optimal to enter the domestic market.

This essay relates to the theoretical literature of patent licensing where several issues have been extensively studied. The literature can be traced back to Arrow (1962) who argued that a perfectly competitive industry provides a higher incentive to innovate than a monopoly. The authors refer to Kamien (1992) for a survey of the early literature. Comparing licensing by means of upfront fees (which may be collected via an auction) and royalties, the early literature concluded that licensing by means of upfront fees dominates royalty licensing for an outside innovator (Kamien \& Tauman, 1984; Kamien \& Tauman, 1986; Kamien, et al., 1992). As royalties are frequently observed in practice, the conclusion on the suboptimality of royalty licensing generated a number of papers that argued that royalties can be explained by factors, such as informational asymmetry (Gallini \& Wright, 1990; Rockett, 1990; Sen, 2005a), product differentiation (Muto, 1993; Wang \& Yang, 1999; Poddar \& Sinha, 2004), leadership structure (Kabiraj, 2004; Kabiraj, 2005; Filippini, 2005), or by the fact that the number of licenses must be an integer (Sen, 2005b). There is a small literature that considers issues of international trade in the context of technology transfer. Mukherjee (2001) shows that a lump-sum subsidy to domestic firms may encourage a foreign firm to license its technology. Kabiraj and Marjit (2003) find that tariffs on foreign firms may also induce technology transfer.

In the existing literature, the status of the patent-holding firm (outsider or insider) is exogenously fixed. One contribution of this essay is to indigenize this option. The authors show that if an outside patent-holding firm is given the choice of staying outside or entering the industry, then under Cournot competition, the outside patent holding firm always finds that it is optimal to enter.

The rest of this paper is organized as follows. The authors describe the model in section 2. Section 3 derives the optimal licensing policies of the foreign firm when it stays outside the domestic market. Section 4 derives the optimal policies when it enters the domestic market, and then compares the equilibrium prices. The optimal entry strategy for the foreign firm is determined in section 5 . We conclude in section $6{ }^{1}$

\section{The model}

The authors consider a Cournot duopoly in a country with two firms firm 1 and firm 2, which producing the same product. Let $q_{1}$ and $q_{2}$ be the respective quantities produced by firm 1 and firm 2 and let $Q=q_{1}+q_{2}$. Let $P$ be the market price. The inverse demand function of the industry is given by $P=a-Q$ if $Q<a$, and $P=0$ if $Q \geq a$.

There is an existing technology under which both firms produce at the identical constant marginal cost $c$, where $0<c<a$. An outside innovator, which is a foreign firm (we call it firm 3), has been granted a patent for a new technology that reduces the cost from $c$ to $c-\varepsilon$, where $0<\varepsilon<c$. The notion of drastic innovation (Arrow, 1962 ) is useful for our analysis. A cost-reducing innovation is drastic if the monopoly price under the new technology falls below the cost under the old technology; Otherwise, it is non-drastic. If only one firm in an oligopoly has a drastic innovation, then it becomes a monopolist with the reduced cost and all other firms drop out

\footnotetext{
1 All proofs are straightforward, hence they are omitted. They are available upon request.
} 
of the market. For the model under consideration, the innovation of firm 3 is drastic if $\varepsilon \geq a-c$, and it is non-drastic if $\varepsilon<a-c$. To keep the problem of technology transfer non-trivial, the authors assume throughout that the innovation is non-drastic, i.e., $\varepsilon<a-c$.

Firm 3 can license the new technology to one or both of firm 1 and firm 2. The authors consider two standard licensing policies: (1) The auction policy: Firm 3 sells licenses through an auction policy (where a licensee pays an upfront fee which is collected through an auction). It is well-known in the literature of patent licensing (see, e.g., Katz \& Shapiro, 1986; Kamien \& Tauman, 1986) that the best way to collect an upfront fee is via an auction; (2) The unit royalty policy: Firm 3 sells licenses by announcing a unit royalty. Any licensee pays the specified royalty to firm 3 for each unit that it produces. The authors consider two possible entry options for firm 3: (1) It licenses the technology by staying outside; (2) It enters the market, licenses the technology and then competes with firm 1 and firm 2.

\section{Licensing by staying outside}

The strategic interaction when firm 3 stays out is modeled as an extensive-form game $G_{0}$. This game has three stages. In the first stage, firm 3 announces a licensing policy to sell the license to one or both of the other firms. In the second stage, firm 1 and firm 2 decide whether to accept the policy or not. The set of licensees becomes commonly known in the end of stage 2. In the third stage, firm 1 and firm 2 compete in quantities, where any licensee operates under the new technology and any non-licensee operates under the old technology. The solution concept is the notion of Subgame Perfect Nash Equilibrium (SPNE) which is obtained by standard backward induction method.

\subsection{Auction policy}

The authors begin with the auction policy. As the innovation is non-drastic, in equilibrium, any firm (regardless of whether it has cost $c^{-} \varepsilon$ or $c$ ) produces positive output. The following lemma identifies the (unique) Nash Equilibrium for any resulting oligopoly.

Lemma 1: Let $k=1,2$. Consider a Cournot duopoly with firm 1 and firm 2 under inverse demand (1), and let $\varepsilon<a-c$. Suppose $k$ firms have $\operatorname{cost} c-\varepsilon$ and the remaining $2-k$ firms have cost $c$. This duopoly has a unique Nash Equilibrium (NE). Let $q_{W}(k)$ and $\Phi_{W}(k)$ denote the NE output and profit of a firm with cost $c-\varepsilon$. Let $q_{L}(k)$ and $\Phi_{L}(k)$ be the corresponding expressions for a firm that has cost $c$. Then the following hold:

(1) $k=1: q_{W}(1)=\frac{a-c+2 \varepsilon}{3}$ and $\Phi_{W}(1)=\left[q_{W}(1)\right]^{2}, q_{L}(1)=\frac{a-c-\varepsilon}{3}$ and $\Phi_{L}(1)=\left[q_{L}(1)\right]^{2}$;

(2) $k=2: \quad q_{W}(2)=\frac{a-c+\varepsilon}{3}$ and $\Phi_{W}(2)=\left[q_{W}(2)\right]^{2}$.

Auction policy with $k=1$ :

When firm 3 announces to auction off only one license, in equilibrium, both firm 1 and firm 2 place the same $\operatorname{bid} B(1)$ which equals the willingness to pay for a license. It is given by:

$$
B(1)=\Phi_{W}(1)-\Phi_{L}(1)=\frac{(a-c+2 \varepsilon)^{2}}{9}-\frac{(a-c-\varepsilon)^{2}}{9}
$$

One of the firm 1 or firm 2, is chosen at random to be the sole licensee. Firm 3's equilibrium payoff is its revenue from licensing. Since it obtains the equilibrium bid $B(1)$ from the sole licensee, the licensing revenue is simply $B(1)$. So the payoff of firm 3 for $k=1$ is: 
Auction policy with $k=2$ :

$$
\Pi(1)=B(1)=\frac{(a-c+2 \varepsilon)^{2}}{9}-\frac{(a-c-\varepsilon)^{2}}{9}
$$

When firm 3 announces to two licenses, it has to specify a minimum bid. Without a minimum bid, no firm will place a positive bid since each one is guaranteed to have a license. When $k=2$, the willingness to pay for a license is:

$$
B(2)=\Phi_{W}(2)-\Phi_{L}(1)=\frac{(a-c+\varepsilon)^{2}}{9}-\frac{(a-c-\varepsilon)^{2}}{9}
$$

Here the authors subtract $\Phi_{L}(1)$, because a firm can reduce the number of licenses from two to one by refusing to have a license. For $k=2$, the optimal minimum bid is $B(2)$. In equilibrium each of the firm 1 and firm 2 bid exactly $B(2)$. As before, firm 3's equilibrium payoff is its revenue from licensing. Since it obtains the equilibrium bid $B(2)$ each licensee and there are two licensees, the licensing revenue is $2 B(2)$. So the payoff of firm 3 for $k=2$ is:

$$
\Pi(2)=2 B(2)=2\left[\frac{(a-c+\varepsilon)^{2}}{9}-\frac{(a-c-\varepsilon)^{2}}{9}\right]
$$

Proposition 1: Suppose firm 3 has a non-drastic cost-reducing innovation, i.e., $\varepsilon<a-c$. If firm 3 licenses by staying outside the industry, then its optimal auction policy is given as follows:

If $0<\varepsilon \leq \frac{2}{3}(a-c)$, the optimal policy is $k=2$ where firm 3 obtains:

$$
\Pi(2)=2\left[\frac{(a-c+\varepsilon)^{2}}{9}-\frac{(a-c-\varepsilon)^{2}}{9}\right]
$$

If $\frac{2}{3}(a-c)<\varepsilon<a-c$, the optimal policy is $k=1$ where firm 3 obtains:

$$
\Pi(1)=\frac{(a-c+\varepsilon)^{2}}{9}-\frac{(a-c-\varepsilon)^{2}}{9}
$$

\subsection{Royalty policy}

Under the royalty policy with rate of royalty $r$, the effective unit cost of a licensee becomes $c-\varepsilon+r$. If $r>\varepsilon$, then this effective unit cost exceeds $c$ (the cost without the innovation), so no firm will buy a license. We can then restrict $0 \leq r \leq \varepsilon$. In that case, both firm 1 and firm 2 accept the offer.

Lemma 2: Consider a Cournot duopoly with firm 1 and firm 2 under inverse demand (1) and let $\varepsilon<a-c$. Suppose both firms have $\operatorname{cost} c-\varepsilon+r$ where $0 \leq r \leq \varepsilon$. This duopoly has a unique Nash Equilibrium (NE). For $i=1,2$, let $q_{i}(r)$ and $\Phi_{i}(r)$ denote the NE output and profit of firm $i$. Then the following hold:

$$
q_{1}(r)=q_{2}(r)=\frac{a-c+\varepsilon-r}{3} \text { and } \Phi_{1}(r)=\Phi_{2}(r)=\left[q_{1}(r)\right]^{2}
$$

Using Lemma 2, the payoff of firm 3 under rate of royalty $r$ is:

$$
\Pi_{R}(r)=r\left[q_{1}(r)+q_{2}(r)\right]=2 r \frac{(a-c+\varepsilon-r)}{3}
$$

Proposition 2: Suppose firm 3 has a non-drastic cost-reducing innovation, i.e., $\varepsilon<a-c$. If firm 3 licenses by staying outside the industry, then its optimal royalty policy is to set $r=\varepsilon$. The payoff under the optimal royalty policy is:

$$
\Pi_{R}^{*}=\frac{2}{3} \varepsilon(a-c)
$$

\subsection{Optimal licensing policy for firm $\mathbf{3}$ when it stays outside}

Proposition 3: Suppose firm 3 has a non-drastic cost-reducing innovation, i.e., $\varepsilon<a-c$. If firm 3 stays 
outside, then the auction policy is always superior to the royalty policy. Consequently, its optimal licensing policy is given as follows:

If $0<\varepsilon \leq \frac{2}{3}(a-c)$, then the optimal policy is the auction policy with $k=2$ where firm 3 obtains:

$$
\Pi(2)=2\left[\frac{(a-c+\varepsilon)^{2}}{9}-\frac{(a-c-\varepsilon)^{2}}{9}\right]
$$

If $\frac{2}{3}(a-c)<\varepsilon<a-c$, then the optimal policy is the auction policy with $k=1$ where firm 3 obtain:

$$
\Pi(1)=\frac{(a-c+\varepsilon)^{2}}{9}-\frac{(a-c-\varepsilon)^{2}}{9}
$$

\section{Firm 3 enters the domestic market}

Consider the case where firm 3 enters the industry, licenses its technology and then competes with firm 1 and firm 2. Let $q_{1}, q_{2}$ and $q_{3}$ be the respective quantities produced by firm 1 , firm 2 and firm 3, and let $Q=q_{1}+q_{2}+q_{3}$ be the industry output. The strategic interaction among firm 1, firm 2 and firm 3 is modeled as the extensive-form game $G_{1}$. This game has three stages: In the first stage, firm 3 announces a licensing policy to sell the license to one or both of the other firms; In the second stage, firm 1 and firm 2 decide whether to accept the policy or not. The set of licensees becomes commonly known in the end of stage 2; In the third stage, firm 1, firm 2 and firm 3 compete in quantities, where firm 3 and any licensee operates under the new technology and any non-licensee operates under the old technology. The solution concept is the notion of Subgame Perfect Nash Equilibrium (SPNE).

\subsection{Auction policy}

Lemma 3: Let $k=1,2$. Consider a Cournot oligopoly with firms 1, 2, 3 under inverse demand (2) and let $\varepsilon<a-c$. Suppose firm 3 has cost $c-\varepsilon, k$ other firms have cost $c-\varepsilon$ and the remaining $3-k$ firms have cost $c$. This oligopoly has a unique Nash Equilibrium (NE). Let $q_{W}(k)$ and $\Phi_{W}(k)$ denote the NE output and profit of a firm with cost $c-\varepsilon$. Let $q_{L}(k)$ and $\Phi_{L}(k)$ be the corresponding expressions for a firm that has cost $c$. Then the following hold:

(1) $k=1: \quad q_{W}(1)=\frac{a-c+2 \varepsilon}{4}$ and $\Phi_{W}(1)=\left[q_{W}(1)\right]^{2}, \quad q_{L}(1)=\frac{a-c-2 \varepsilon}{4}$ and $\Phi_{L}(1)=\left[q_{L}(1)\right]^{2} ;$

(2) $k=2: \quad q_{W}(2)=\frac{a-c+\varepsilon}{4}$ and $\Phi_{W}(2)=\left[q_{W}(2)\right]^{2}$.

Auction policy with $k=1$ :

When firm 3 announces to auction off only one license, in equilibrium, both firm 1 and firm 2 place the same bid $B(1)$ which equals the willingness to pay for a license. It is given by:

$$
B(1)=\Phi_{W}(1)-\Phi_{L}(1)=\frac{(a-c+2 \varepsilon)^{2}}{16}-\frac{(a-c-2 \varepsilon)^{2}}{16}
$$

One of the firms, 1 or 2, is chosen at random to be the sole licensee. Firm 3's equilibrium payoff for $k=1$ is:

$$
\Pi(1)=\Phi_{W}(1)+B(1)=\frac{(a-c+2 \varepsilon)^{2}}{16}+\left[\frac{(a-c+2 \varepsilon)^{2}}{16}-\frac{(a-c-2 \varepsilon)^{2}}{16}\right]=2 \frac{(a-c+2 \varepsilon)^{2}}{16}-\frac{(a-c-2 \varepsilon)^{2}}{16}
$$

Auction policy with $k=2$ :

When firm 3 announces to two licenses, it has to specify a minimum bid. When $k=2$, the willingness to pay for a license is: 


$$
B(2)=\Phi_{W}(2)-\Phi_{L}(1)=\frac{(a-c+\varepsilon)^{2}}{16}-\frac{(a-c-2 \varepsilon)^{2}}{16}
$$

Here we subtract $\Phi_{L}(1)$, because a firm can reduce the number of licenses from two to one by refusing to have a license. For $k=2$, the optimal minimum bid is $B(2)$. In equilibrium, each of firm 1 and firm 2 bid exactly $B(2)$. Firm 3's equilibrium payoff for $k=2$ is:

$$
\Pi(2)=\Phi_{\mathrm{W}}(2)+2 \mathrm{~B}(2)=\frac{(a-c+\varepsilon)^{2}}{16}+2\left[\frac{(a-c+\varepsilon)^{2}}{16}-\frac{(a-c-2 \varepsilon)^{2}}{16}\right]=3 \frac{(a-c+\varepsilon)^{2}}{16}-2 \frac{(a-c-2 \varepsilon)^{2}}{16}
$$

Proposition 4: Suppose firm 3 has a non-drastic cost-reducing innovation, i.e., $\varepsilon<a-c$. If firm 3 enters the industry, then its optimal auction policy is given as follows:

If $0<\varepsilon \leq \frac{2}{9}(a-c)$, the optimal policy is $k=2$ where firm 3 obtains:

$$
\Pi(2)=3 \frac{(a-c+\varepsilon)^{2}}{16}-2 \frac{(a-c-2 \varepsilon)^{2}}{16} ;
$$

If $\frac{2}{9}(a-c)<\varepsilon<a-c$, the optimal policy is $k=1$ where firm 3 obtains:

$$
\Pi(1)=2 \frac{(a-c+2 \varepsilon)^{2}}{16}-\frac{(a-c-2 \varepsilon)^{2}}{16} .
$$

\subsection{Royalty policy}

Under the royalty policy with rate of royalty $r$, the effective unit cost of a licensee becomes $c^{-} \varepsilon+r$. If $r>\varepsilon$, then this effective unit cost exceeds $c$ (the cost without the innovation), so no firm will buy a license. We can then restrict $0 \leq r \leq \varepsilon$. In that case, both firm 1 and firm 2 accept the offer. As before, firm 3 operates under the unit $\operatorname{cost} c-\varepsilon$.

Lemma 4: Consider a Cournot oligopoly with firm 1, firm 2 and firm 3 under inverse demand (2), and let $\varepsilon<a-c$. Suppose firm 3 has cost $c-\varepsilon$, and each of firm 1 and firm 2 has $\cos t c-\varepsilon+r$ where $0 \leq r \leq \varepsilon$. This oligopoly has a unique Nash Equilibrium (NE). For $i=1,2,3$, let $q_{i}(r)$ and $\Phi_{i}(r)$ denote the NE output and profit of firm $i$. Then, the following hold:

$$
\begin{gathered}
q_{1}(r)=q_{2}(r)=\frac{a-c+\varepsilon-2 r}{4} \text { and } \Phi_{1}(r)=\Phi_{2}(r)=\left[q_{1}(r)\right]^{2} \\
q_{3}(r)=\frac{a-c+\varepsilon+2 r}{4} \text { and } \Phi_{3}(r)=\left[q_{3}(r)\right]^{2}
\end{gathered}
$$

Using Lemma 4, we can determine the payoff of firm 3 under rate of royalty $r$, which is given by:

$$
\Pi_{\mathrm{R}}(r)=\Phi_{3}(r)+r\left[q_{1}(r)+q_{2}(r)\right]=\frac{(a-c+\varepsilon+2 r)^{2}}{16}+2 r \frac{(a-c+\varepsilon-2 r)}{4}
$$

Proposition 5: Suppose firm 3 has a non-drastic cost-reducing innovation, i.e., $\varepsilon<a-c$. If firm 3 enters the industry, then its optimal royalty policy is to set $r=\varepsilon$. The payoff under the optimal royalty policy is $\Pi_{R}^{*}=\frac{(a-c+3 \varepsilon)^{2}}{16}+2 \varepsilon \frac{(a-c-\varepsilon)}{4}$. In particular, the payoff from optimal royalty policy is strictly higher than its payoff from no licensing.

\subsection{Optimal licensing policy for firm 3 when it enters the industry}

Proposition 6: Suppose firm 3 has a non-drastic cost-reducing innovation, i.e., $\varepsilon<a-c$. If firm 3 enters the industry, then its optimal licensing policy is given as follows: 
If $0<\varepsilon \leq \frac{2}{3}(a-c)$, then the optimal policy is the royalty policy with $r=\varepsilon$, where firm 3 obtains:

$$
\Pi_{R}^{*}=\frac{(a-c+3 \varepsilon)^{2}}{16}+2 \varepsilon \frac{(a-c-\varepsilon)}{4}
$$

If $\frac{2}{3}(a-c)<\varepsilon<a-c$, then the optimal policy is the auction policy with $k=1$, where firm 3 obtains:

$$
\Pi(1)=2 \frac{(a-c+2 \varepsilon)^{2}}{16}-\frac{(a-c-2 \varepsilon)^{2}}{16}
$$

Proposition 7: Suppose firm 3 has a non-drastic cost-reducing innovation, i.e., $\varepsilon<a-c$. Let $p^{o}(\varepsilon)$ be the Cournot prices under the optimal licensing policy of firm 3 when it stays outside the domestic market, and let $p^{E}(\varepsilon)$ be the price under its optimal licensing policy when it enters the domestic market. Then the following hold:

$$
\begin{aligned}
& \text { If } 0<\varepsilon<\frac{1}{5}(a-c) \text {, then } p^{E}(\varepsilon)<p^{O}(\varepsilon) ; \\
& \text { If } \frac{1}{5}(a-c) \leq \varepsilon \leq \frac{2}{3}(a-c) \text {, then } p^{O}(\varepsilon) \leq p^{E}(\varepsilon) ; \\
& \text { If } \frac{2}{3}(a-c)<\varepsilon<a-c \text {, then } p^{E}(\varepsilon)<p^{O}(\varepsilon) \text {. }
\end{aligned}
$$

\section{Optimal entry strategy for firm 3}

Proposition 8: Suppose firm 3 has a non-drastic cost-reducing innovation, i.e., $\varepsilon<a-c$. It is always optimal for firm 3 to enter the industry and then license its technology as follows:

If $0<\varepsilon \leq \frac{2}{3}(a-c)$, then the optimal post-entry licensing policy is the royalty policy with $r=\varepsilon$, where firm 3 obtains:

$$
\Pi_{R}^{E}=\frac{(a-c+3 \varepsilon)^{2}}{16}+2 \varepsilon \frac{(a-c-\varepsilon)}{4}
$$

If $\frac{2}{3}(a-c)<\varepsilon<a-c$, then the optimal post-entry licensing policy is the auction policy with $k=1$, where firm 3 obtains:

$$
\Pi^{E}(1)=2 \frac{(a-c+2 \varepsilon)^{2}}{16}-\frac{(a-c-2 \varepsilon)^{2}}{16}
$$

\section{Conclusion}

In this work, the authors have considered a simple Cournot duopoly model where there are two competing domestic firms. An outside foreign firm has a patent on a new technological innovation that can reduce the costs of all firms. The foreign firm has the option of licensing its technology to the domestic firms by staying outside the industry, or it can enter the industry, license its technology and compete with the domestic firms. The authors show that if the foreign firm transfers its technological innovation by staying outside, its optimal licensing policy is an auction policy, which is an upfront fee policy where the fee is collected via an auction. However, if the foreign firm licenses the technology by entering the industry, then for relatively insignificant innovations, it is optimal to use for royalties, while for relatively significant innovations, it is best to use an auction policy. Finally, 
determining the entry strategies of the foreign firm by taking its optimal licensing policies into account, we show that it is always optimal for the foreign firm to enter.

One of the interesting conclusions is that the Cournot price is lower with entry for innovations that are very insignificant and very significant, while for innovations of moderate magnitudes, the Cournot price is lower when the foreign firm stays outside. This non-monotonicity is due to the fact that the foreign firm's optimal licensing policy potentially differs depending on whether it enters the domestic market or not. When it stays outside, it is always optimal to use auction policy that makes a licensee firm very efficient. In contrast, when it enters the industry, it may be optimal to use royalties which keeps the licensees inefficient. Entry by the (more efficient) foreign firm has a direct competitive effect, but if entry is accompanied by royalties on domestic firms, it can distort the competitive effect. The results suggest that licensing policies play an important role in determining whether technology transfer together with entry leads to a lower price compared to technology transfer without entry by the patent-holding foreign firms.

A natural extension of the model would be to consider the case where the domestic market has an oligopoly with $n$ firms rather than only two firms. It would be also of interest to see the extent to which our results are robust to changes in the mode of competition.

\section{References:}

Arrow, K. J.. (1962). Economic welfare and the allocation of resources for invention. In: Nelson, R. R. (Ed.), The rate and direction of inventive activity: Economic and social factors. Princeton University Press, 609-625.

Filippini, L.. (2005). Licensing contract in a stackelberg model. The Manchester School, 73, 582-598.

Gallini, N. T. \& Wright, B. D.. (1990). Technology transfer under asymmetric information. RAND Journal of Economics, 21, $147-160$

Kabiraj, T.. (2004). Patent licensing in a leadership structure. The Manchester School, 72, 188-205.

Kabiraj, T.. (2005). Technology transfer in a stackelberg structure: Licensing contracts and welfare. The Manchester School, 73, 1-28.

Kabiraj, T. \& Marjit, S.. (2003). Protecting consumers through protection: The role of tariff-induced technology transfer. European Economic Review, 47, 113-124.

Kamien, M. I.. (1992). Patent licensing. In: Aumann, R. J. \& Hart, S. (Eds.), Handbook of game theory with economic applications. North Holland: Elsevier Science, 331-354 (Chapter 11).

Kamien, M. I. \& Tauman, Y.. (1984). The private value of a patent: A game theoretic analysis. Journal of Economics, Supplement, 4, 93-118.

Kamien, M. I. \& Tauman, Y.. (1986). Fees versus royalties and the private value of a patent. Quarterly Journal of Economics, 101, $471-491$.

Kamien, M. I. \& Tauman, Y.. (2002). Patent licensing: The inside story. The Manchester School, 70, 7-15.

Kamien, M. I., Oren, S. S. \& Tauman, Y.. (1992). Optimal licensing of cost-reducing innovation. Journal of Mathematical Economics, $21,483-508$.

Mukherjee, A.. (2002). Subsidy and entry: The role of licensing. Oxford Economic Papers, 54, 160-171.

Muto, S.. (1993). On licensing policies in bertrand competition. Games and Economic Behavior, 5, 257-267.

Rockett, K.. (1990). The quality of licensed technology. International Journal of Industrial Organization, 8, $559-574$.

Sen, D.. (2005a). On the coexistence of different licensing schemes. International Review of Economics and Finance, 14, $393-413$.

Sen, D.. (2005b). Fee versus royalty reconsidered. Games and Economic Behavior, 53, 141-147.

Wang, X. H. \& Yang, B. Z.. (1999). On licensing under bertrand competition. Australian Economic Papers, 38, $106-119$.

(Edited by Ruby and Chris) 